\title{
Sindemia, infodemia, pandemia de COVID-19: Hacia una pandemiología de enfermedades emergentes
}

\author{
Syndemic, infodemic, pandemic of COVID-19: \\ Towards a pandemiology of emerging diseases
}

'PhD en Epidemiología. Investigador $1-A$

Conselho Nacional de

Desenvolvimento Científico

e Tecnológico (CNPq).

Profesor Titular jubilado, Instituto de Saúde Coletiva,

Universidade Federal da

Bahia. Profesor Visitante,

Instituto de Estudos

Avançados Universidade de

São Paulo, Brasil. $\bowtie$ iD
Naomar de Almeida-Filho'

RESUMEN Como base para una teoría de la coocurrencia de procesos epidémicos y pandémicos, en primer lugar, se introduce el concepto de sindemia, creado en la epidemia de $\mathrm{VIH} /$ sida para comprender componentes sociales, conductuales y culturales de enfermedades emergentes, tal como la actual pandemia de COVID-19. En segundo lugar, se destaca la noción de infodemia, que tiene gran potencial para comprender los impactos de la pandemia desde planos que generalmente se descuidan en los enfoques epidemiológicos convencionales. En tercer lugar, como complemento e ilustración, se presenta un estudio de caso "microarqueológico" de la infodemia resultante de la pandemia de COVID-19, centrado en la situación concreta de Brasil. Luego, se analizan las correlaciones entre la evidencia científica, los modelos de intervención y las medidas para controlar la pandemia en varios países y su adopción o rechazo en la realidad brasileña, estructurada sobre profundas desigualdades económicas, inequidades sociales e inequidades en salud.

PALABRAS CLAVES Sindemia; Pandemias; COVID-19; Enfermedades Emergentes; Brasil.

\begin{abstract}
As the basis for a theory of the co-occurrence of epidemic and pandemic processes, the article begins with a discussion of the concept of syndemic, created during the HIV/AIDS epidemic to understand the social, behavioral, and cultural components of emerging diseases, as is the case of the current COVID-19 pandemic. Secondly, the notion of infodemic is highlighted, which has great potential to better understand the impacts of the pandemic from approaches that are generally neglected in conventional epidemiological research. Third, in order to illustrate these points, a "micro-archaeological" case study of the infodemic resulting from the COVID-19 pandemic is presented, focusing on the specific situation in Brazil. Then, the correlations between scientific evidence, intervention models, and measures to control the pandemic are comparatively analyzed in different countries, as well as their adoption or rejection in the Brazilian context, which is structured by deep economic inequalities, social inequities, and health inequities.
\end{abstract}

KEY WORDS Syndemic; Pandemics; COVID-19; Emerging Diseases; Brazil. 


\section{INTRODUCCIÓN}

Al inicio de la pandemia de COVID-19, pensadores y teóricos sociales de varios países del hemisferio norte se apresuraron a demarcar territorios filosóficos y políticos. Cuando el continente europeo sufría intensamente una avalancha de casos y muertes, con el caos instalado en los sistemas de salud y las crisis económicas y políticas, esos intelectuales se alinearon para abordar diferentes aspectos de la catástrofe anunciada recientemente. Con relatos pertinentes, aunque a veces parciales y apresurados, grandes nombres del pensamiento contemporáneo aprovecharon la pandemia para revisitar sus respectivos sistemas y modelos conceptuales ${ }^{(1)}$. Hubo de todo: desde la confusión inicial al pesimismo inercial, desde el optimismo mediático al escepticismo teórico, desde la denuncia de las distopías al voluntarismo prescriptivo, desde el análisis político a la especulación metafísica. No obstante, por más políticamente progresistas que puedan parecer algunos de estos análisis, debemos adoptar una postura contracolonial y contestataria hacia tales discursos -en lo que Walter Mignolo ${ }^{(2)}$ Ilama de desobediencia epistémica, para lograr lo que Boaventura de Sousa Santos propone denominar como epistemologías del sur ${ }^{(3)}$.

Durante décadas se ha construido en América Latina una epidemiología social crítica como un subcampo de investigación y práctica, en un registro de autonomía epistemológica, valorando aspectos teóricos y políticos de la salud pública ${ }^{(4,5)}$. En este registro de no sumisión, condicionado por las contradicciones y callejones sin salida de formaciones sociohistóricas periféricas, desiguales y diversas, académicos y referentes intelectuales se han dedicado a construir redes institucionales, líneas de investigación, referencias científicas y caminos académicos independientes de las formaciones hegemónicas de las ciencias modernas, instituidas en el norte global.

Las pandemias son básicamente epidemias a gran escala. Es decir, son megaepidemias que escapan al control de los órganos y sistemas de protección de la salud pública de su lugar de origen y atraviesan fronteras nacionales, llegando a numerosos países y a varios continentes. Algunos autores contemporáneos denominan estos fenómenos como eventos $\operatorname{críticos}^{(6)}$, otros prefieren la designación de objetos complejos ${ }^{(7)}$. Una pandemia es un evento histórico singular, emergente, totalizado y complejo, como los huracanes, tsunamis, guerras, supernovas y otros fenómenos del mundo y de la vida ${ }^{(8)}$. Se trata de un objeto de conocimiento específico y peculiar que, en definitiva, implica todos estos fenómenos y procesos, articulados con otros elementos de comprensión y análisis, unificados mediante una integración heurística, que no los reduce a mediciones, mediaciones, descripciones, efectos, correlaciones y narrativas.

Con rigor epistemológico, ¿cómo modelar la pandemia de COVID-19, respetando su complejidad, totalidad y singularidad? Para responder a esta pregunta, he propuesto tomar la pandemia de COVID-19 como un objeto-modelo, con base en una solución de modelaje heurístico guiado por planos de ocurrencia e interfaces jerárquicas ${ }^{(9,10)}$. Con el objetivo de comprender el surgimiento del nuevo coronavirus como tema problemático en las ciencias de la salud, es necesario recurrir a nuevos conceptos y explorar sus redes de relaciones significativas y explicativas.

En este artículo, en primer lugar, presento el concepto de sindemia, propuesto como base para una teoría de la coocurrencia de procesos epidémicos, representativa de la forma convencional de entender enfermedades emergentes con fuerte expresión de componentes conductuales y culturales, tal como ha sido antes la pandemia de VIH/ sida y ahora la pandemia de COVID-19. En segundo lugar, entre los conceptos emergentes en este contexto, destaco la noción de infodemia, que tiene un gran potencial para comprender mejor los impactos de la pandemia en los planos de ocurrencia que generalmente se descuidan en los enfoques epidemiológicos convencionales. Tercero, como complemento e ilustración del marco teórico esbozado, presento un estudio de caso "microarqueológico" de la infodemia, 
centrado en la situación concreta de Brasil resultante de la pandemia de COVID-19. En este estudio de caso, analizo además las correlaciones entre la evidencia científica, los modelos de intervención y las medidas para controlar la pandemia en varios países y su adopción o rechazo en la realidad brasileña, estructurada sobre profundas desigualdades económicas, inequidades sociales e inequidades en salud. Finalmente, para enriquecer este esfuerzo de comprensión teórica, propongo formular una perspectiva integradora sobre esta extraña e intrigante pandemia, una posible "pandemiología", capaz de eventualmente contribuir para su confrontación y superación.

En este contexto actual de intensa disputa retórica y reñida lucha teórica, la singularidad y complejidad de la pandemia de Covid-10 representa, sin duda, una rica oportunidad para llevar a cabo de manera efectiva la construcción intertransdisciplinaria tan necesaria para la generación de soluciones integradoras, pertinentes y cuidadosas frente a los problemas complejos que emergen en los diferentes planos y dimensiones de la pandemia ${ }^{(10)}$. Particularmente, con respecto a los procesos concretos de la realidad en salud, los esfuerzos creativos dirigidos a la producción de modelos sintéticos de este orden pueden ser relevantes para la construcción de objetos complejos transdisciplinares. Las propuestas de modelización heurística y la articulación intertransdisciplinar como las aquí propuestas pueden contribuir a una planificación estratégica, no lineal e intensamente participativa, capaz de ayudar a afrontar y superar esta grave crisis sanitaria mundial.

\section{TEORÍA DE LA SINDEMIA}

En el discurso social común y en los principales medios de comunicación, la investigación sobre enfermedades como el COVID-19 en el ámbito biomolecular ha sido más valorada en comparación con las dimensiones clínicas, ambientales, socioculturales, económicas y políticas. Los epidemiólogos y científicos sociales interesados en el campo de la salud han Ilamado la atención sobre cómo las condiciones económicas, políticas y culturales -al actuar como vectores de concentración de la desventaja social, como determinantes de la salud- generan epidemias de varias enfermedades infecciosas agrupadas, que pueden resultar en un exceso del sufrimiento y un aumento de la mortalidad. Por otro lado, los subespacios del sujeto humano, el cuerpo social, la comunidad, el medio ambiente y la cultura, superpuestos e interconectados, superan con creces el potencial explicativo del genoma-proteoma y de las estructuras bioquímicas y metabólicas. En este escenario, factores geopolíticos, relaciones económicas, vectores migratorios, vínculos sociales y prácticas cotidianas son capaces de transformar un brote epidémico en una pandemia, mientras que oleadas de información falsa y decisiones políticas equivocadas pueden resultar en una gran reducción en la capacidad de control de la transmisión comunitaria del nuevo coronavirus.

Recientemente, en un editorial de la revista médica The Lancet, Horton ${ }^{(11)}$ afirmó provocativamente que el COVID-19 es más que una pandemia y, de hecho, se configura como un evento sindémico. Así resaltado en el discurso académico sobre la pandemia de COVID-19, la propuesta de una teoría de las sindemias merece aquí una breve revisión, evaluando su aplicabilidad para comprender sistemas epidemiológicos complejos.

La noción de sindemia fue propuesta por Merrill Singer ${ }^{(12)}$ a finales de la década de 1990, buscando articular los conceptos de comorbilidad e interacción para una mejor comprensión de la pandemia de $\mathrm{VIH} /$ sida. Originalmente, este enfoque teórico se propuso para explicar la variación en la exposición y riesgo al VIH en diferentes comunidades, especialmente en grupos con trastornos por abuso de sustancias que también han tenido experiencias de exposición a la violencia. Posteriormente, se utilizó el enfoque sindémico para explicar las complejas interrelaciones entre la comorbilidad de la depresión con la diabetes y la interacción entre inmigración y violencia en Chicago, 
EEUU ${ }^{(13)}$. Recientemente, la teoría de la sindemia se ha presentado como una fuente de soluciones innovadoras para hacer frente a emergencias humanitarias complejas, evitando la interacción de resultados negativos en los indicadores relevantes de protección y promoción de la salud en crisis sanitarias ${ }^{(14)}$.

En Introduction to syndemics: A critical systems approach to public and community health ${ }^{(15)}$, Singer sistematiza los principales elementos y aplicaciones de la teoría de la sindemia. El principio básico de esta propuesta es que los determinantes ambientales y socioculturales pueden contribuir al aumento del riesgo de condiciones comórbidas $^{(12,15)}$. Singer parte de las ideas de comorbilidad y multidisciplinariedad como base para una reconceptualización de las epidemias en sociedades complejas en tanto sindemias. Como prototipo del concepto de sindemia, presenta lo que denomina SAVA Syndemic, siendo SAVA un acrónimo de Substance Abuse, Violence, AIDS. A partir de ahí extiende este ejercicio para la "sindemia renocardíaca", apuntando al síndrome metabólico, por entonces recientemente descrito. Enfocándose en las enfermedades transmisibles, Singer toma como ejemplo de sindemia la coocurrencia de $\mathrm{VIH} /$ sida con infecciones oportunistas, destacando la tuberculosis. Y, finalmente, al describir la epidemia de SARS de 2002-2003 como un proceso sindémico ${ }^{(15)}$ que tuvo una letalidad aumentada en situaciones de comorbilidad con enfermedades crónicas, anticipa el complejo panorama de la actual pandemia de COVID-19.

La propuesta original de la teoría de la sindemia integra dos conceptos: concentración de enfermedades e interacción de factores ${ }^{(16,17)}$. La concentración de enfermedades se refiere a la comorbilidad o coocurrencia de condiciones patológicas ${ }^{(18,19)}$ y la agrupación o superposición de epidemias como resultado de macroprocesos económicos y políticos. La superposición de enfermedades y epidemias exacerba los efectos de diversas formas de sufrimiento social, en la salud individual y colectiva, ya sea a través de sinergias biológicas entre estados patológicos o mediante interacciones entre procesos biológicos y sociales, como las personas infectadas por VIH que desarrollan tuberculosis activa o la alta incidencia de $\mathrm{VIH} /$ sida entre los usuarios de drogas inyectables. Algunos modelos teóricos prevalentes explican la coexistencia de epidemias en términos de la carga acumulada de enfermedad, pero esta teoría agrega la concepción de que la superposición de epidemias son más que la suma del impacto aislado de las epidemias que componen la sindemia ${ }^{(15,20)}$.

La perspectiva que generó la teoría sindémica se centró solo en la multimorbilidad y destacó las interacciones biológicas a nivel individual. A nivel clínico y epidemiológico, el concepto de comorbilidad había ganado notoriedad por considerar hipótesis etiológicas comunes entre diferentes estados de la enfermedad y por considerar la complejidad del cuidado de pacientes con más de una enfermedad crónica. A nivel poblacional, la interacción con la enfermedad se ha descrito, de modo general, en términos de morbilidad paralela o comorbilidad ${ }^{(18)}$. Desde una perspectiva sindémica, los conceptos de comorbilidad y multimorbilidad son teóricamente más importantes en la clínica, pero también son relevantes para la investigación epidemiológica en el campo de la política y planificación en salud ${ }^{(19)}$. Los modelos existentes de coocurrencia de epidemias se representan, generalmente, sin referencia a las fuerzas sociales que condicionan la exposición. Incluso, cuando se aplican en epidemiología, el foco permanece en la distribución, a nivel individual, de condiciones comórbidas y situaciones sociales vulnerabilizantes tales como factores de riesgo o determinantes en modelos de causalidad $^{(21)}$.

Un desafío conceptual importante, que tiene importantes implicaciones metodológicas, se refiere al nivel de análisis en el que tienen lugar las interacciones. Singer llama la atención sobre el hecho de que la interacción de la enfermedad ocurre tanto en el nivel poblacional como individual y, por implicación, se deben movilizar datos de diferentes niveles de análisis para validar la teoría ${ }^{(15)}$. Los análisis multinivel incorporan efectos individuales, poblacionales y contextuales, pero 
los estudios existentes se centran en factores de nivel individual(21). De hecho, el campo de la investigación epidemiológica se ha centrado en investigar cómo los resultados a nivel individual también pueden explicarse por covariables a nivel individual. Por lo tanto, la falta de estudios de nivel poblacional ha dificultado la producción de conocimiento sobre determinantes sensibles a estrategias eficientes para hacer frente a las sindemias.

Según lo analizado por Tsai et al., ${ }^{(22)}$ la principal utilidad de la teoría de la sindemia es que aborda posibles interacciones no solo entre enfermedades (a nivel individual), sino también entre epidemias (a nivel poblacional), teniendo en cuenta el contexto social y las desigualdades políticas y económicas. En otras palabras, abre espacio y brinda la oportunidad de enfoques teóricos capaces de generar hipótesis sobre cómo las interacciones entre enfermedades, a nivel individual, y epidemias, a nivel poblacional, determinan el impacto social de las enfermedades y cómo los planificadores y gestores de salud pueden intervenir eficazmente para prevenir efectos y mitigar los daños a la salud colectiva. Originalmente centrada en el campo del tratamiento y la prevención del $\mathrm{VIH} / \mathrm{sida}$, la evidencia producida en el contexto del enfoque sindémico se ha utilizado para justificar intervenciones complejas, integradas y/o multidimensionales dirigidas a todas las epidemias que ocurren juntas.

Concebida para abordar problemas teóricos y metodológicos que normalmente evitan los paradigmas tradicionales de la patogénesis, la teoría de la sindemia se presenta como una perspectiva integradora de abordajes disciplinarios diversos en un esfuerzo de investigación articulado e inte$\operatorname{ractivo}^{(22,23,24,25,26,27,28,29,30)}$. Esta perspectiva unificadora, integradora y sobre todo aplicada es lo que hace que la teoría de la sindemia sea relevante para la pandemia de COVID-19. Los investigadores clínicos enfatizan las interacciones entre las condiciones comórbidas que son agigantadas, resentidas entre hospitalizaciones y defunciones por COVID-19, particularmente hipertensión ${ }^{(22)}$, diabetes $^{(23)}$, y obesidad $^{(24)}$. La evidencia emergente sugiere que el COVID-19, por medio de distintos mecanismos aún desconocidos, puede exacerbar el riesgo de enfermedad cardiometabólica ${ }^{(22)}$. Estudios realizados principalmente en EEUU indican que la pandemia de COVID-19 involucra dos tipos de interacciones: a) interacciones biológicas entre comorbilidades (diabetes, hipertensión y COVID-19), y b) interacciones biosociales entre condiciones sociales dañinas y procesos biológicos involucrados en la progresión de la infección por SARS-CoV-2 al riesgo de COVID-19. De hecho, las distinciones conceptuales entre estos dos modelos implican diferentes estrategias para hacer frente a la pandemia, priorizando la prevención y el control de la transmisión frente al tratamiento y la mitigación de daños.

La teoría sindémica conecta las perspectivas individuales y poblacionales entre el COVID-19 y las desigualdades sociales y raciales preexistentes que pueden exacerbar el sufrimiento de enfermedades crónicas, tales como la hipertensión y diabetes ${ }^{(25)}$. De hecho, los mismos sistemas fisiológicos que producen sinergias entre hipertensión, diabetes y COVID-19 también están involucrados en las correlaciones que vinculan la desventaja económica con las desigualdades raciales y sociales en la hipertensión y diabetes. A nivel ecosocial, las condiciones estructurales determinan una mayor morbilidad y mortalidad por COVID-19 en comunidades que ya sufren con pobreza, desigualdad racial y exclusión social ${ }^{(25,26,27)}$.

No obstante la pertinencia y relevancia de esta propuesta, conviene señalar aquí sus límites y problemas, que pueden ser contemplados y quizás superados por un enfoque teórico basado en las teorías de la complejidad. En este sentido, en mi opinión, a pesar de su pertinencia y oportunidad, manifestada en su ambición epistemológica, la teoría de la sindemia puede ser objeto de crítica teórica, en cinco aspectos:

a. No avanza hacia la intertransdisciplinariedad, restringiéndose a la multidisciplinariedad, tanto en lo que se refiere al concepto ampliado de salud, como al 
objeto "enfermedad", tomado como plural y multifacético: es a la vez defecto, lesión, alteración, patología, dolencia, riesgo, daño, enfermedad, en los diferentes planos de ocurrencia.

b. Aporta una visión superficial de la perspectiva multinivel o multicomponente, sin extender su comprensión a planos de emergencia e interfaces jerárquicas que proporcionan un modelo complejo de los objetos y temas-problemas de las ciencias de la salud.

c. Adopta una posición restringida de causalidad, al no considerar procesos patológicos, estados de salud y correlatos como sobredeterminados por el complejo de flujos y fuerzas emergentes (causas, factores, determinantes, vectores) o por la acción articulada de diferentes conjuntos determinantes, y por los valores que asumen estas transformaciones con relación a la resistencia (capacidades, resiliencia, fuerza, entre otros) de la dimensión afectada (célula, órgano, cuerpo, grupo, medio, entre otros).

d. La teoría de la sindemia adopta una posición sociopolítica conservadora en el tratamiento teórico de las desigualdades sociales como determinantes no jerárquicos del conjunto de fenómenos relacionados con la salud que afectan a los cuerpos, seres y poblaciones humanas en sociedades históricas.

e. Finalmente, expresa una evidente omisión de temas referentes a las dimensiones e interfaces en los planos económico, político y cultural-simbólico, que podrían completar y justificar la perspectiva sindémica de la pandemia.

La teoría de la sindemia, particularmente el concepto de coocurrencia de enfermedad e interacción multifactorial, involucra múltiples niveles de análisis e interseccionalidad entre determinantes, lo que la hace bastante congruente con la perspectiva de la holopatogenesis ${ }^{(31)}$. A pesar de sus límites, este marco conceptual tiene el potencial de contribuir a la comprensión de la transformación de la pandemia del nuevo coronavirus ${ }^{(10)}$. Para ello, en los planos teórico y metodológico, será necesario complementar algunos de sus vacíos y reemplazar elementos conceptuales esenciales, especialmente en la interfaz político-cultural, dado el desborde teórico de los fenómenos sindémicos asociados al COVID-19 $9^{(32)}$.

Con el objetivo de generar una mayor eficiencia explicativa de estos modelos, yendo más allá de la explicación causal de los fenómenos biológicos y ecológicos, centrándose en subespacios e interfaces de planos supraindividuales, se han propuesto algunos abordajes basados en conceptos emergentes, como la noción de sindemia analizada anteriormente y las ideas de infodemiología e infodemia que se destacan a continuación.

\section{INFODEMIOLOGÍA E INFODEMIA EN LA PANDEMIA}

Particularmente en lo que respecta a la pandemia de COVID-19, Iriarte y Pompei ${ }^{(33)}$ nos recuerdan que, más allá de la pandemia y la sindemia, también es necesario considerar lo que llegó a denominarse "infodemia".

Poco después de la declaración oficial de que el COVID-19 era una pandemia, en febrero de 2020, la Organización Mundial de la Salud (OMS) advirtió que, en paralelo, el mundo se enfrentaba a una infodemia a gran escala. La revista científica The Lancet se hizo eco de la advertencia de la OMS, en un editorial titulado How to fight an infode$\mathrm{mic}^{(34)}$. En el contexto prepánico del inicio de la pandemia de COVID-19, el tema y su denominación cobró repercusión mundial inmediata: el 31/01/2021 realicé una búsqueda en Google con el marcador <infodemic covid-19> que llegó a 12.600 resultados; en la misma fecha, en el sitio web de PubMed, identifiqué 145 artículos publicados en revistas científicas en un intervalo de 11 meses. Este rápido aumento en las menciones de una idea (que habría subvencionado un neologismo prácticamente desconocido) provocó el comentario de Patel et al.. ${ }^{(35)}$ de que la infodemia de COVID-19 sería "más pandémica que el virus". 
En el apogeo de la moda de la informática médica, en 2002, el científico de datos germano-canadiense Gunther Eysenbach publicó en la revista American Journal of Medicine un artículo titulado Infodemiology: The epidemiology of (mis)information, proponiendo una "epidemiología de la información", con el objetivo de estudiar sistemáticamente los patrones de información y comunicación en medios electrónicos ${ }^{(36)}$. En ese momento, al prescribir una infodemia descriptiva y una infodemia analítica, representativas de versiones obsoletas de la epidemiología, la propuesta parecía hasta una analogía grosera, casi una parodia, de la ciencia epidemiológica.

Posteriormente, Eysenbach ${ }^{(37)}$ retomó su propuesta, justificándola con un cliché publicitario de dudoso gusto (low quality information on the Internet could be detrimental to public health - informaciones de baja calidad en Internet pueden ser perjudiciales para la salud pública) y recomendando el uso de datos "infodemiológicos" con fines de vigilancia, lanzando la extraña idea de la "infoveillance". La infodemiologia fue definida por este autor como "la ciencia de la distribución y determinantes de la información" en Internet o en la población. Para actualizar la analogía original, el autor propuso un curioso reflejo de algunos indicadores epidemiológicos, como "prevalencia de información" (information prevalence), "prevalencia de conceptos" (concept prevalence) y "razones de ocurrencia de conceptos" (concept occurrence ratios).

A pesar de numerosos indicios de poca consistencia teórica y evidentes problemas conceptuales, la propuesta logró encontrar espacio en la VI edición del tradicional Dictionary of Epidemiology, donde se encuentra la entrada correspondiente, debidamente rectificada con la sustitución de "ciencia" por "estudio"(38):

Infodemiología: El estudio de la distribución de la información y sus determinantes en un medio electrónico, específicamente en Internet, o en una población, con el objetivo de informar políticas públicas y de salud. Ejemplos incluyen el análisis a partir de motores de búsqueda en internet para predecir los brotes de enfermedades, herramientas automatizadas para medir la difusión de la información y la translación del conocimiento, y el monitoreo de la efectividad de las campañas de marketing en salud (ver infovigilancia). [Infodemiology: The study of the distribution of information and its determinants in an electronic medium, specifically the Internet, or in a population, with the aim to inform public health and public policies. Examples include the analysis of queries from Internet search engines to predict disease outbreaks, automated tools to measure information diffusion and knowledge translation, and tracking the effectiveness of health-marketing campaigns. (See also infoveillance)].

El término "infodemia" proviene de la expresión "information epidemic", una simple condensación de las palabras información + epidemia. Curiosamente, a pesar de la rápida referencia a un tipo de "epidemics of fear ${ }^{\prime \prime(37)}$, no se menciona ese término en los textos propositivos de "infodemiología" La palabra infodemia fue utilizada por primera vez por David Rothkopf, periodista del Washington Post, en un artículo sobre el brote de SARS en $2003^{(39)}$, para analizar los peligros del fenómeno de la desinformación, que podría obstaculizar la respuesta social frente a procesos epidémicos y amenazas a la seguridad pública como, por ejemplo, el terrorismo. En sus palabras ${ }^{(39)}$ :

¿Qué quiero decir exactamente con infodemia? Algunos hechos, mezclados con miedo, especulaciones y rumores, amplificados y transmitidos rápidamente en todo el mundo por las modernas tecnologías de la información, han afectado a las economías, la política e incluso la seguridad nacional e internacional en formas totalmente desproporcionadas con las realidades arraigadas. Es un fenómeno que hemos visto con mayor 
frecuencia en los últimos años, no solo en nuestra reacción al SARS, por ejemplo, sino también en nuestra respuesta al terrorismo e incluso a sucesos relativamente menores, como avistamientos de tiburones. [What exactly do I mean by the "infodemic"? A few facts, mixed with fear, speculation and rumor, amplified and relayed swiftly worldwide by modern information technologies, have affected national and international economies, politics and even security in ways that are utterly disproportionate with the root realities. It is a phenomenon we have seen with greater frequency in recent years - not only in our reaction to SARS, for example, but also in our response to terrorism and even to relatively minor occurrences such as shark sightings].

Rothkopf ${ }^{(39)}$ continúa reforzando su propuesta de una analogía entre epidemias de enfermedades y epidemias de desinformación, o infodemias, con una actualidad y pertinencia impresionantes:

La infodemia emerge como uno de los fenómenos más virulentos conocidos por el hombre, capaz de transitar continentes instantáneamente. Prácticamente en todos los aspectos se comportan como cualquier otra enfermedad, con una epidemiología propia, síntomas identificables, portadores bien conocidos e incluso curas tradicionales. Sin embargo, hasta la fecha, muchos en el poder parecen incapaces de contenerla o no están dispuestos a reconocer su existencia. Estos virus de transmisión por vía internet o los medios de comunicación crean pánico global, desencadenan un comportamiento irracional, nublan nuestra visión de problemas subyacentes importantes, sobrecargan nuestra infraestructura, obstaculizan los mercados y socavan a los gobiernos. Sin embargo, gestionadas y entendidas, las fuerzas que impulsan la infodemia pueden ayudarnos a crear mejores sistemas de alerta temprana para todo, desde enfermedades hasta disturbios sociales, así como a responder rápidamente y monitorear los resultados. [Infodemics are emerging as one of the most virulent phenomena known to man, able to transit continents instantly. In virtually every respect they behave just like any other disease, with an epidemiology all their own, identifiable symptoms, well-known carriers, even straightforward cures. Yet to date many in power seem unable to contain them or unwilling to acknowledge their existence. These Internet- or mediaborne viruses create global panics, trigger irrational behavior, blur our vision of important underlying problems, strain our infrastructure, buffet markets and undermine governments. Managed and understood, however, the forces that fuel infodemics can help us create better early warning systems for everything from diseases to social unrest, as well as respond quickly and monitor the results].

En julio de 2020, reconociendo la existencia y gravedad de la infodemia ligada a la pandemia de COVID-19, la OMS promovió la I Conferencia de Infodemiología de la OMS, con la participación de 110 expertos de todos los continentes. Los participantes del evento definieron oficialmente la "infodemiología" como la ciencia de la gestión de la infodemia y concluyeron que la pandemia de desinformación exigía una respuesta amplia, coordinada y multidisciplinaria. En este evento se señalaron cuatro pilares para la gestión de la infodemia: 1) seguimiento de la información ("infovigilancia"); 2) fortalecer la capacidad de alfabetización en salud digital y ciencia; 3) fomentar los procesos de mejora de la calidad de la información, como la verificación de datos y la revisión por pares; y 4) traducción precisa y oportuna del conocimiento, minimizando factores distorsionantes como influencias políticas o comerciales ${ }^{(40)}$.

En septiembre de 2020, las organizaciones del sistema de Naciones Unidas (OMS, UNICEF, PNUD, UNESCO, ONUSIDA, UIT, ONU Global Pulse, Federación Internacional de Sociedades de la Cruz Roja y de la Media 
Luna Roja) emitieron una declaración conjunta titulada Managing the COVID-19 infodemic. Con el declarado objetivo de reducir los daños causados por la desinformación y contribuir así al control de la pandemia, este documento ${ }^{(41)}$ busca mostrar el impacto crítico del nuevo entorno de información caracterizado por las plataformas de medios sociales y las redes comunitarias virtuales, en los que la diseminación de desinformaciones puede influir significativamente en el comportamiento de las personas y cambiar la eficacia de las contramedidas implementadas por los gobiernos. Al mes siguiente, como parte de esta iniciativa global, la OPS/OMS anunció una convocatoria pública de artículos para un número especial de la Revista Panamericana de Salud Pública sobre "Infodemiología y manejo de la infodemia en la era de la interdependencia digital"(42).

Para los organismos de la United Nations, la pandemia de COVID-19 es la primera en la historia en la que se han utilizado tecnologías digitales a gran escala para mantener a las personas bien informadas, productivas $y$ seguras $y$, al mismo tiempo, alimentar una infodemia que, a escala global compromete las medidas para controlar la pandemia. A partir de constatar que la desinformación puede ser perjudicial para la salud física y mental de las personas al aumentar la estigmatización, la xenofobia y el racismo, y reducir la efectividad de las medidas para controlar la pandemia, los autores de esta declaración instaron $\mathrm{a}^{(41)}$ :

La información incorrecta trunca vidas. Sin la confianza y la información correcta adecuadas, las pruebas diagnósticas se quedan sin utilizar, las campañas de inmunización (o de promoción de vacunas eficaces) no cumplirán sus metas y el virus seguirá medrando. Además, la información falsa polariza el debate público sobre los temas relacionados con la COVID-19; da alas al discurso de odio; potencia el riesgo de conflicto, violencia y violaciones de los derechos humanos; y amenaza las perspectivas a largo plazo de impulsar la democracia, los derechos humanos y la cohesión social
[Misinformation costs lives. Without the appropriate trust and correct information, diagnostic tests go unused, immunization campaigns (or campaigns to promote effective vaccines) will not meet their targets, and the virus will continue to thrive. Furthermore, disinformation is polarizing public debate on topics related to COVID-19; amplifying hate speech; heightening the risk of conflict, violence and human rights violations; and threatening long-terms prospects for advancing democracy, human rights and social cohesion.

Esto se completa con las declaraciones del responsable del Programa de las Naciones Unidas para el Desarrollo (PNUD), Achim Steiner:
A medida que los países comiencen a recuperarse de la pandemia del COVID- 19 y nos reunamos para enfrentar sus devastadores efectos socioeconómicos, la comunidad internacional debe garantizar que la lucha contra la infodemia no ter- mine solo porque la pandemia haya ter- minado. [När länder börjar återhämta sig från covid-19-pandemin och vi samlas för att hantera dess förödande socio-ekono- miska effekter måste det internationella samfundet se till att bekämpandet av info- demin inte tar slut bara för att pandemin är över]. ${ }^{(43)}$

La declaración conjunta de los organismos de las Naciones Unidas ${ }^{(41)}$ presentó una definición descriptiva y pragmática de la idea de "infodemia" como "una abundancia excesiva de información", incluidos los "intentos deliberados" de difundir información errónea, dirigidos a "adelantar agendas alternativas de grupos o individuos", cuyo resultado será socavar la respuesta social a la crisis de salud pública. Desde esta perspectiva, el problema de la infodemia, por tanto, no sería solo el volumen o exceso de información, sino la propia validez y veracidad de estas informaciones, implicando mala calidad y mala intención, con errores inducidos y flagrante 
parcialidad política en los procesos de desinformación ${ }^{(44)}$. En síntesis, existe una fuerte e implícita correlación entre el concepto de fake-news y la idea de infodemia. Sin embargo, mientras que el primer término ha sido objeto de estudios basados en teorías críticas de la comunicación y la información ${ }^{(45,46,47)}$, con detallados análisis del discurso y del impacto social, político y cultural, la noción de infodemia todavía carece de un fundamento teórico consistente y de un tratamiento científico adecuado.

La historia de las disputas narrativas sobre la "verdad de los hechos", que generó lo que se ha llamado (con varios toques de ironía) de posverdades, es el tema de un delicado ensayo de Robert Darnton, titulado The true history of fake news ${ }^{(45)}$, publicado poco después de las elecciones presidenciales estadounidenses de 2016. El impacto de esta verdadera "information war" en el contexto político de la sociedad digital puede ser devastador, tanto desde el punto de vista de la estabilidad institucional de las democracias como, en el plano cultural-simbólico, en lo que se refiere al deterioro de las relaciones interpersonales ${ }^{(46)}$. En un análisis retórico de las infames fake-news, Paul Levinson ${ }^{(47)}$ demostró que existe conciencia e intención por parte de los individuos involucrados en la producción y divulgación de noticias falsas, con el objetivo preciso y deliberado de desinformar en contextos de disputa política, que de otro modo son una amenaza para el orden democrático.

En este registro de convergencia, como hipótesis, postulo que los procesos sindémicos e infodémicos críticos de la nueva pandemia de coronavirus fueron, en el contexto brasileño, inducidos por políticas gubernamentales definidas por una adhesión activa, consciente y publicitada, en un patrón relativamente consistente de respuestas estratégicas institucionales. En conjunto, incluso de manera burda y subordinada, tales respuestas fueron mimetizadas de algunos otros países que, de modo correspondiente y articulado, estaban en ese momento sufriendo las penurias de una coyuntura política regresiva. Se trata de países cuyos gobiernos adoptaron un marco político conservador y autoritario, que Lasco llamó de medical populism ${ }^{(48)}$, cultivando y propagando matrices ideológicas oscurantistas y fundamentalistas desde un punto de vista cultural (particularmente en el ámbito religioso), y negacionistas, especialmente en lo que respecta al conocimiento científico establecido.

\section{INFODEMIA: BRASIL COMO ESTUDIO DE CASO}

En esta sección, me propongo analizar la dinámica imaginario-social de la pandemia de COVID-19, con la ayuda de una línea de tiempo construida a partir de la identificación de narrativas marcadas por correspondencias entre evidencia científica, modelos de intervención y estrategias de estructuración retórica de los funcionarios y autoridades, discurso sobre las medidas de control en diferentes países y su posterior adopción o rechazo en el país denominado Brasil. Desde una perspectiva microhistórica, realicé una revisión narrativa, buscando constatar si las evaluaciones de evidencias, suficientes para la toma de decisiones orientadas por la ciencia, fueron efectivamente realizadas y eventualmente continuadas, prestando atención a las consecuencias en el corto, mediano y largo plazo para la sociedad brasileña. En términos metodológicos, el objetivo de este caso de estudio será analizar posibles inconsistencias y alineamientos conceptuales, niveles de planificación y medidas operativas que afectaron la naturaleza, calidad y tiempo de respuesta del gobierno federal y los gobiernos de las entidades federativas, estados y municipios subnacionales. Este análisis de la retórica oficial se complementó con una valoración de los núcleos discursivos de la narrativa producida por líderes y agentes políticos.

Durante el transcurso de la pandemia, aparentemente de manera deliberada, en muchos aspectos y de diversas maneras, los dirigentes políticos incurrieron en graves equívocos y omisiones, en una sucesión de 
errores, actos imprudentes que resultaron en sufrimientos y muertes totalmente innecesarios. Sin embargo, el principal eje de acción de estos líderes y sus redes de apoyo fue la promoción continua de una potente campaña de desinformación sobre la pandemia de COVID-19, utilizando la infodemia como estrategia necropolítica ${ }^{(49)}$. Del triste repertorio de esta infodemia inducida, destaqué para el análisis una peculiar medida no farmacológica que fue designada como "aislamiento vertical".

Desde el inicio de la pandemia de COVID-19 en Brasil, la idea del "aislamiento vertical" fue propuesta y defendida por el presidente de la República y sus asistentes ${ }^{(50)}$. Con la expectativa de lograr la "inmunidad de rebaño", pretendían suspender las medidas generales de control epidemiológico, aislando solo a los grupos vulnerables, los ancianos y las personas con comorbilidades. Poco después del anuncio de esta extraña idea, investigadores de diversas disciplinas cuestionaron inmediatamente su validez científica. Con algunos colegas epidemiólogos, hice una búsqueda cuidadosa y no encontré nada en las publicaciones científicas y médicas. En la teoría epidemiológica no existe un concepto de este orden, mucho menos su opuesto simétrico, el "aislamiento horizontal", vagamente referido a la cuarentena y al distanciamiento físico como estrategia general para la reducción del contagio.

Desde el punto de vista epidemiológico, no tiene sentido utilizar una cuarentena invertida, aplicada solo a los vulnerables y no a los infectados, sin mencionar que una gran parte de la población brasileña vive en condiciones en las que sería difícil o imposible aislar a alguien en la casa. La libre circulación de sujetos contaminantes, sintomáticos o no, facilitaría el contagio y la pandemia estaría fuera de todo control, pudiendo volverse endémica. Además de ser científicamente inválida, esta estrategia también es problemática desde el punto de vista de la ética médica, ya que implica un gerontocidio anunciado, dada la mayor virulencia y letalidad del COVID-19 entre los ancianos ${ }^{(51)}$. En resumen, por estas y otras razones, la extraña noción de "aislamiento vertical" no se sustenta ni encuentra referencia en los campos científicos de la medicina y de la salud pública.

Dicho esto, la pregunta sigue siendo: ¿Cómo se pudo haber constituido una noción tan perversa? Para intentar responderla, desde una perspectiva "microarqueológica", necesitamos en retrospectiva, partir de su primera formulación más sistemática, con fecha en los últimos días de marzo del primero año de la pandemia.

- 26/03/2020. Osmar Terra, congresista, exministro de Estado, es entrevistado en una cadena de radio nacional. Primero, presenta sus credenciales como médico y exsecretario de salud que, según él, habría enfrentado y vencido epidemias mucho más graves que la pandemia de COVID-19. Al tratar de explicar cuestiones técnicas en un lenguaje sencillo, muestra su supuesta experiencia gerencial y su supuesto fundamento técnico, como si estuviera postulando a algún cargo. Enérgicamente, sin vacilar, afirma que la población brasileña ya habría alcanzado niveles de "inmunidad de rebaño" suficientes para justificar el relajamiento de las medidas de "distanciamiento social". Para él, controlar la pandemia "no tiene nada que ver con cerrar escuelas, centros comerciales, prohibir el transporte público [...] hay que proteger a las personas más debilitadas, que tienen enfermedades crónicas, este es el grupo que hay que aislar". Confirma que esta es "la posición del presidente Bolsonaro, con base en evidencia científica, en información del Ministerio de Salud, que defiende el aislamiento vertical".

- 25/03/2020. Instagram @governodobrasil: "En todo el mundo son raros los casos de víctimas fatales de \#coronavirus. La casi totalidad de las defunciones se dio en ancianos. Por lo tanto, es necesario proteger a estas personas y a todos los integrantes de los grupos de riesgo, con todo cuidado, cariño y respeto. Para estos, aislamiento. Para todos los demás, distanciamiento, atención redoblada y mucha responsabilidad. Vamos a volver a la normalidad, con cuidado 
y consciencia. \#oBrasilNãoPodeParar. Ese mismo día, en una entrevista, el presidente declara: "La orientación será el aislamiento vertical a partir de ahora, es decir, los ancianos y los que tengan dos o más enfermedades". Propone retomar la actividad económica, para evitar que "la cura sea peor que la propia enfermedad".

- 24/03/2020. En un comunicado en la televisión nacional, el presidente afirma que la enfermedad será "en el mejor de los casos, una gripecita", que tendrá poco efecto en la población brasileña, capaz de, según él, producir espontáneamente resistencia al coronavirus. Introduce en el discurso presidencial la noticia de que está buscando "pruebas de la eficacia de la cloroquina en el tratamiento del COVID-19". Anteriormente, ante los primeros indicios de la pandemia, su primera y, durante mucho tiempo, única respuesta fue "promover el uso masivo de este antimalárico, ordenando su fabricación en instalaciones militares".

Considerando que el Dr. Henrique Mandetta, entonces ministro de Salud, propuso seguir las orientaciones de la OMS (lo que luego le costaría la humillación pública y exoneración del cargo), ¿dónde habría encontrado el presidente capitán (que pasó por el ejército desde 1973 hasta su expulsión en 1986) una justificación técnica para su mensaje a la nación? ¿Quién le enseñó a deletrear "cloroquina" y "aislamiento vertical"? No fue difícil encontrar una pista: el expresidente Donald Trump.

Retrocedamos en el tiempo, en rápidas capas geológicas de narrativas:

- 24/03/2020. Donald Trump propone flexibilizar las medidas de control de la pandemia en EEUU; para ello, promete un plan para reabrir la economía en Semana Santa. Postea en su twitter personal: we cannot let the cure be worse than the problem itself. Traducción: "no podemos dejar que la cura sea peor que el problema en sí". ¿Suena conocido?
Como se puede ver, el expresidente armamentista tampoco es conocido por su sabiduría y creatividad. Dado que el médico Anthony Fauci, coordinador de la task-force para combatir la pandemia en EEUU, recomendaba seguir directrices científicas del CDC y de la WHO, zquién habría ayudado a Trump con su retórica? Incluso aquí no fue difícil encontrar a los sospechosos habituales: un presentador de televisión, un columnista de un periódico tradicional y un asesor de dietas y suplementos dietéticos.

- 23/03/2020. Steve Hilton, presentador de Fox News, refiriéndose a la economía, lanza al aire su muletilla "the cure is worse than the disease", de inmediato adoptada por el entonces presidente Trump, que pasa a utilizarla regularmente.

- 22/03/2020. Thomas Friedman publica en su coluna en el New York Times un artículo titulado A plan to get America back to work [Plan para que América vuelva a trabajar] ${ }^{(52)}$ en donde advierte sobre la necesidad de desarrollar una estrategia más "quirúrgica" de control de la pandemia, minimizando daños económicos. El considera "one of the best ideas" [una de las mejores ideas] la "vertical interdiction" [interdicción vertical] propuesta por un nutricionista llamado David Katz.

- 20/03/2020. Katz publica en el New York Times un texto de opinión titulado Is our fight against Coronavirus worse than the disease?(53) [¿Será nuestra lucha contra el coronavirus peor que la enfermedad?]. Autopresentándose como director-fundador del Yale-Griffin Prevention Research Center y presidente de una ONG Ilamada True Health Initiative, Katz patenta y promueve su creación: "interdicción vertical". En el sentido de las normas para controlar el contagio dentro de las familias, esta noción se opondría a otra estrategia que él describe como: "una táctica que llamo "interdicción horizontal", cuando las políticas de contención se aplican a toda la población sin considerar su riesgo de infección severa". 
David Katz no es epidemiólogo, ni especialista en enfermedades infecciosas, ni virólogo. La prestigiosa Universidad de Yale se apresuró a declarar que, desde 2019, Katz había sido destituido como director del Griffin Hospital Prevention Research Center. Epidemiólogos e investigadores médicos de varias universidades han escrito artículos que refutan el artículo de Katz. Incluso hay una carta al editor del New York Times. Adam Gabatt, en un artículo de The Guardian del $27 / 03 / 2020^{(54)}$, informaba que Katz es un especialista en consultoría nutricional, autor de libros de autoayuda alimentaria, con títulos sugerentes como The way to eat, cut your cholesterol y stealth health. Además, tiene notorios vínculos con la gran industria alimenticia cobrando cientos de miles de dólares a empresas como Hershey's, Kind Bars, Quaker Oats, y otras no divulgadas, como experto en litigios y para escribir artículos positivos sobre sus productos.

En la jerga epidemiológica, diríamos que encontramos el caso índice o paciente cero. En el nuevo lenguaje de la infodemiología, encontramos la fuente del fraude.

La velocidad de esta pandemia ideológica es impresionante: en solo seis días, un virus de desinformación atraviesa hemisferios y amenaza la política de toda una nación, la salud de toda una población y la vida de toda una generación. En la infodemia del COVID-19, la cadena de contagio KatzFriedman-Hilton-Trump-Bolsonaro-Terra es bastante evidente, más aún al rastrear la transferencia de esta pésima metáfora de la "cura que mata" en paralelo con una versión simplista de la vieja y bizarra idea de “inmunidad de rebaño"(55). Pero hay un pequeño e intrigante detalle, quizás una inconsistencia en esta hipótesis arqueológica: ¿se trata, después de todo, de prohibición o aislamiento? La respuesta puede estar en la conexión Miami-Brasilia-condominios de Barra da Tijuca, considerando las limitaciones lingüísticas de los Bolsonaros. Los anglosajones tienen una expresión muy adecuada para esta situación: lost in translation [perdido en la traducción].
En resumen: en una infodemia ${ }^{(56)}$, tan peligrosas como las fake-news son las mentiras y las medias verdades, cuando se manipulan en juegos de lenguaje, falaces y maliciosos. Las mentiras se desenmascaran en más o menos tiempo, los malentendidos y las verdades a medias finalmente se aclaran, las falacias se pueden deconstruir (con mayor o menor esfuerzo). Pero hay casi un consenso generalizado de que es muy difícil combatir la deshonestidad retórica incrustada en argumentos que contienen pseudoverdades, supuestamente basadas en evidencia científica, porque el sujeto que las enuncia tiene mala fe y quien las propaga actúa de manera socialmente irresponsable. En fin, la idea del aislamiento vertical constituye un tosco fraude pseudocientífico, cruel y extremadamente peligroso.

Blanco de la impugnación teórica, metodológica y ética por parte de investigadores, instituciones académicas y organismos de salud pública, la idea del "aislamiento vertical" permaneció viva solo en el discurso lego y en los medios de comunicación. A pesar de ello, en sincronía con la demostración de la ineficacia de los Ilamados tratamientos preventivos, basados en antipalúdicos, antihelmínticos y desinfectantes, esta idea pareció resurgir al final del año pandémico, debidamente reciclada.

- 04/10/2020. En una celebración con brindis de champagne, con una fuerte campaña mediática, se dio a conocer un manifiesto titulado The Great Barrington Declaration, liderado por tres investigadores de reconocidas universidades ${ }^{(57)}$. En nombre de la libertad individual, la propuesta Ilamaba a todas las personas, tanto a aquellas con menor riesgo de morir por COVID-19, así como a los miembros de grupos de riesgo, a retomar sus actividades profesionales normales y su vida diaria, asistiendo a bares y restaurantes, a eventos deportivos, artísticos y culturales, si así lo deseaban.

El texto de esta declaración festiva hace una referencia positiva a la "inmunidad de rebaño", afirmando que una mayor transmisión 
de la enfermedad entre las personas con menor riesgo eventualmente contribuirá al control de la pandemia. Casi en passant, relanza el concepto de "interdicción vertical", ahora rebautizado como focused protection, o "protección focalizada", indicando que las autoridades sanitarias deberían viabilizar y reforzar el aislamiento estricto de las personas mayores y portadores de comorbilidades. La iniciativa (y su marketing ostensible) fue financiada por American Institute for Economic Research, un think tank conservador vinculado a una red de organizaciones asociadas al negacionismo del cambio climático ${ }^{(58)}$. Suscrita por unos pocos miles de seguidores, incluidos robots digitales y personajes ficticios, desenmascarados en cuanto fueron identificados, la declaración cuenta, entre sus primeros firmantes, con el Sr. David Katz.

Volvamos a Brasil. La pandemia golpeó a este país en medio de una agenda de reforma política centrada en la austeridad fiscal y la reducción del papel del Estado en la economía. Como consecuencia de los recortes de gastos y las reformas de ajuste neoliberal, especialmente la reforma laboral y previsional, contrariamente al pregonado crecimiento económico, se ha acentuado la situación del desempleo, la crisis y el deterioro de los indicadores fiscales. La política de austeridad también desfinanció el SUS y fragilizó la estructura de protección social en un contexto de aumento de la pobreza y las desigualdades sociales. Por el contrario, con la pandemia, las políticas económicas, asistenciales, de salud y seguridad pública necesitarían mitigar el efecto de las desigualdades de todo tipo, desigualdades de género, raza/etnia, clase social, y territoriales ${ }^{(59)}$. Las medidas de distanciamiento físico y cuarentena son muy difíciles de seguir por la población pobre, con trabajadores informales, autónomos o desempleados. Hay millones de brasileños que viven en áreas aglomeradas, en casas precarias, en las afueras de las grandes ciudades. A estas personas les cuesta permanecer aisladas en sus casas durante semanas, principalmente porque carecen de recursos para todo: comida, alquiler, agua, energía. Además, es necesario atender a pacientes crónicos y grupos prioritarios como mujeres embarazadas y lactantes, así como a grupos en situación de vulnerabilidad como las poblaciones indígenas, las ribereñas o los grupos quilombolas. Una pandemia como esta sin duda profundiza las desigualdades sociales, generando un aumento de la vulnerabilidad social, las inequidades en salud y las violaciones a los derechos humanos, que afectan directamente a grupos poblacionales oprimidos y discriminados e, indirectamente, a todos los pobres y excluidos del país ${ }^{(59,60)}$.

En Brasil, la pandemia causada por el nuevo coronavirus solo acentuó una serie de graves problemas generados por las desigualdades sociales en la situación de salud de los brasileños. De hecho, incluso antes de la pandemia de COVID-19, los problemas relacionados con el financiamiento, la gestión y la calidad del sistema de salud pública se vieron agravados por la reciente crisis económica, social y política. En el sector público, los aspectos organizativos de los programas e instituciones de salud han producido obstáculos materiales e institucionales que generan inequidades y segregación, disparidades de rentas y de inserción social, en el acceso a los recursos asistenciales disponibles, además de la brecha en la información determinada por las diferencias de género, generación, educación e ingresos. En la primera década de este siglo, personas de clases y grupos sociales desfavorecidos, generalmente residentes en áreas remotas, anteriormente excluidas, lograron un mayor acceso a la atención de salud, especialmente en el nivel de atención primaria, a través de la Estrategia de Salud Familiar. A pesar de esto, las personas con mayor vulnerabilidad social siguieron teniendo dificultades para utilizar los programas de protección y recuperación de la salud, especialmente en los niveles de atención secundaria y terciaria, ampliamente disponibles para los sectores sociales beneficiados con mejores condiciones de vida y por la cobertura de los planes de salud privados ${ }^{(60)}$.

Además del recrudecimiento de las cuestiones ya conocidas, la pandemia de COVID-19 reveló nuevas formas de desigualdades, inequidades e iniquidades. A pesar de ser acogidos en el sistema, las personas de 
segmentos sociales vulnerables y típicamente más necesitadas de una atención de calidad, comenzaron a sufrir desigualdades internalizadas en los propios actos de cuidado, producto de la estructura y funcionamiento del sistema y la realización de prácticas asistenciales de poca efectividad y menor grado de humanización. Estos sujetos se vieron, y se ven a sí mismos, incluso porque eso no ha cambiado, en la condición de usuarios de una categoría inferior en un sistema de salud pública supuestamente universal. Esta ruptura de la calidad-equidad, esta nueva modalidad de "inequidad internalizada", de naturaleza cualitativa, cotidiana, intrafuncional y camuflada, se ejerce a través de formas sutiles y culturalmente sensibles de relaciones intersubjetivas inhumanas, segregadoras y discriminatorias ${ }^{(61)}$.

En varias ocasiones, el presidente Jair Bolsonaro junto a muchos líderes oficiales, promovieron la ruptura de cuarentenas y medidas de distanciamiento, fomentando las aglomeraciones y el rechazo de dispositivos de protección individual. Además, estos líderes han alentado el uso de tratamientos de eficacia no comprobada para el COVID-19, incluyendo en esa lista un antihelmíntico de uso veterinario, un remedio para piojos y sarna, un enema rectal de ozono ${ }^{(62)}$. En el caso de la cloroquina antipalúdica, esto solo indicaría irresponsabilidad, si no hubiera costado vidas y sufrimientos, dado que esta droga incluso produce efectos secundarios fatales (lamentablemente no estudiados como consecuencia de la iatrogenia específica de la pandemia), además de representar un enorme desvío de recursos públicos y energía institucional. El ejército brasileño fabricó millones de comprimidos de cloroquina, suministros para décadas de tratamiento contra la malaria, mucho más allá de la validez de la droga. Con estos medicamentos, las empresas farmacéuticas aprovecharon la oportunidad para aumentar precios y ganancias. Al final de cuentas, el resultado fue un desabastecimiento de anestésicos, antiinflamatorios, anticoagulantes y sedantes, que son esenciales para tratar pacientes graves con
COVID-19 en cuidados intensivos en el Sistema Único de Salud ${ }^{(63)}$.

Al hacer frente a la pandemia, algunos estados y municipios habían mostrado mayor sensibilidad con relación al problema que el gobierno federal. El esfuerzo realizado por algunas pocas administraciones estatales y municipales para expandir la capacidad instalada de camas mediante la apertura de camas de cuidados intensivos fue realmente notable. Pero esta estrategia enfrenta problemas o límites obvios para controlar la pandemia. Más que hospitales de campaña, se necesitarían servicios ambulatorios eficientes, unidades intermedias equipadas y centros de cuidados intensivos o de derivación para estas unidades, servicios de apoyo diagnóstico y terapéutico adecuados, con equipos completos, con medidas correctas de protección individual y colectiva ${ }^{(59)}$.

Los estados y municipios, en general, no han logrado utilizar las redes de atención primaria de salud, con un abordaje comunitario y participativo necesario para enfrentar la pandemia. La actividad de los equipos de atención primaria debería promover una vigilancia epidemiológica efectiva en los territorios para bloquear y reducir el riesgo de expansión de la epidemia, coordinando las acciones de prevención del COVID-19, con identificación de casos, testeo y búsqueda activa de contactos, además del apoyo al aislamiento estricto de casos y contactos. Pero esto solo podría hacerse con apoyo y coordinación nacional, con inteligencia y organización centralizada, lo que en ningún momento se observó en el gobierno federal ${ }^{(59)}$.

Como primer paso, verifiqué los patrones de respuesta de los países donde la trayectoria cronológica de la pandemia precedió a la ocurrencia de los primeros casos y muertes en el territorio nacional, utilizando datos de estudios recientes. Buscando el contraste analítico de la situación brasileña con estos modelos, realicé una cartografía de las políticas gubernamentales en términos de la naturaleza de la respuesta del Estado y su efectividad/tiempo, enfocándome principalmente en el campo de la retórica. En esta etapa, identifiqué seis modelos (tipos 
Tabla 1. Estrategias de enfrentamiento a la pandemia de COVID-19, años 2020-2021.

\begin{tabular}{|ll}
\hline I. Inteligencia epidemiológica & $\begin{array}{l}\text { Control y bloqueo de las cadenas de transmisión, utilizando estrategias de vigilancia } \\
\text { epidemiológica con test, rastreo y aislamiento de casos e infectantes. }\end{array}$ \\
\hline II. Tecnologías sociales & $\begin{array}{l}\text { Reducción del contagio mediante intervenciones sociales obligatorias (cuarentenas, } \\
\text { restricción de movilidad, reducción de la interacción social, distancia física), versión más } \\
\text { radical: confinamiento/lockdown. Medidas no farmacológicas. }\end{array}$ \\
\hline III. Mitigación de daños & $\begin{array}{l}\text { Reducción de daños, con prevención de complicaciones y muertes, mediante la } \\
\text { organización de una retaguardia hospitalaria intensiva, en una lógica de prevención } \\
\text { terciaria. }\end{array}$ \\
\hline IV. Protección individualista & $\begin{array}{l}\text { Medidas de protección personal (uso de máscaras, prácticas higiénicas, equipo de } \\
\text { protección individual, etc.), voluntarias o inducidas, justificadas por la libertad individual. }\end{array}$ \\
V. Aislamiento vertical & $\begin{array}{l}\text { Aislamiento de los grupos más vulnerables, buscando generar una "inmunidad de } \\
\text { rebaño" espontánea. }\end{array}$ \\
VI. Tecnologías farmacológicas & Vacunas, anticuerpos, antivirales, antiinflamatorios, otros. \\
\hline Fuente: Elaboración propia. &
\end{tabular}

ideales) para hacer frente a la pandemia de COVID-19 en diferentes países (Tabla 1).

Utilicé esta tipología ad-hoc para comparar la estrategia adoptada por diferentes niveles de gobierno e instancias de gestión del sistema de salud en Brasil con los estándares globales de conducción frente a la pandemia de COVID-19 ${ }^{(64)}$.

Los países que utilizaron el modelo I, solo o en combinación con el modelo II, como China, Corea del Sur, Uruguay, Nueva Zelanda y Noruega, obtuvieron mejores resultados en el control de la pandemia. Los países que siguieron el modelo II, a menudo en combinación con el modelo III, como la mayoría de los países de la Unión Europea (Alemania, Portugal, España, Francia y los Países Bajos) y algunos países de América del Sur, como Argentina, Chile y África, obtuvieron una amplia variedad de resultados, a menudo sin el sustento de controles epidemiológicos. Países que básicamente siguieron el modelo III, en algunas etapas incorporando elementos o fases del modelo IV, como Inglaterra, Bélgica, Suecia, México, Perú y Colombia, en general, lograron resultados negativos. Países que apostaron por el modelo IV, con algunos elementos del modelo III, como Estados Unidos, Rusia, India y Brasil, son ejemplos de fracaso en el enfrentamiento de la pandemia. El modelo $\mathrm{VI}$, vehiculizado más recientemente y centrado principalmente en el desarrollo de vacunas de diferentes tipos, se ha utilizado en combinación con todos los demás tipos ideales, excepto el modelo $\mathrm{V}$, que tiene el sabotaje antivacunas como una de las modalidades del negacionismo.

La forma en que el gobierno brasileño ha enfrentado la pandemia de COVID-19, hasta ahora, ha mostrado ser incompetente, irresponsable $y$, en muchos sentidos, trágica. La Presidencia de la República tendría constitucionalmente el deber del Estado de proteger la salud pública. Las autoridades, ministros y secretarios de salud tendrían la obligación de formular políticas de control, aportar recursos, viabilizar los recursos, gestionar procesos y coordinar acciones. Sin embargo, el ejecutivo federal nunca elaboró un plan nacional para combatir la pandemia de manera seria desde el punto de vista técnico-científico. Desde esta perspectiva, en la hipótesis más optimista, los posibles y supuestos conflictos, malentendidos, desencuentros y descoordinación en la formulación y ejecución de políticas podrían interpretarse como equívocos que se convirtieron en fracasos. En la hipótesis más realista, se trata de movimientos estratégicos en una necropolítica deliberada, con boicot e incluso hasta sabotaje para enfrentar la crisis de salud del COVID-19 en Brasil. 


\section{HACIA UNA PANDEMIOLOGÍA}

Para comprender la pandemia de COVID-19 y sus impactos reales e imaginarios, desde una perspectiva crítica, autónoma y situada en nuestro propio contexto, es necesario profundizar precisamente en aquellas dimensiones e interfaces que, en este momento, constituyen ausencias y omisiones en los procesos hegemónicos de producción de conocimiento científico y técnico, ciegos a la problemática de la complejidad. Problematizar la complejidad de la pandemia significa, más que nunca, buscar referencias conceptuales, metodológicas y praxiológicas en las matrices de pensamiento del sur global. Se trata de construir una plataforma epistemológica basada en el realismo crítico y praxiológico, integrando la formulación teórica y la práctica militante.

Convocado por la pandemia y sus pesares, Boaventura de Sousa Santos escribió recientemente un libro sobre la sociedad pospandémica, titulado $O$ futuro começa agora: Da pandemia à utopia ${ }^{(65)}$. Con base en el análisis de los múltiples elementos y facetas de la pandemia, luego de un breve repaso histórico, Boaventura aplica de manera competente y consistente su teoría del Estado capitalista, colonialista y patriarcal, al presentar una prospección de escenarios de políticas públicas para combatir la pandemia en diferentes países. En un capítulo extraordinario, nos presenta tres escenarios plausibles para un mundo pospandémico. En sus palabras, los escenarios son: 1) todo como antes y peor: el capitalismo abismal y el estado de seguridad de excepción; 2) piel capitalista, máscara socialista: el nuevo neokeynesianismo; 3) barbarie o civilización: alternativas al capitalismo, el colonialismo y el patriarcado. En una rápida apreciación, considero el escenario 1 como indeseable, el escenario 2 como inviable y el escenario 3 en el registro de los posibles sueños. El propio Boaventura identifica esta última hipótesis con el kairos de la antigüedad griega, "un tiempo que se desdobla en dos temporalidades, el tiempo utópico de la imaginación de nuevos paradigmas y el tiempo histórico de la transición paradigmática". Este escenario implica una superación dialéctica de la contradicción entre civilización y barbarie, necesaria para construir y negociar una salida para el futuro del mundo, en manos ( $y$ en la mente) de aquellos y aquellas que, en la historia colonial, siempre fueron excluidos, segregados, oprimidos, silenciados y negados como bárbaros. Para afrontar los desafíos de esta superación, Boaventura nos propone denunciar y luchar contra las omisiones, represiones e intervenciones de Estados y gobiernos, en el registro del fascismo social, implicados en genocidios y epistemicidios en todo el mundo supuestamente civilizado. Los Ilamados civilizados de hoy serían los bárbaros habituales. Los desarrollos y posibilidades de este escenario constituyen subsidios para un manifiesto esperanzador sobre los anhelos de que una humanidad mejor pueda emerger de la pesadilla de la pandemia.

En este trabajo ${ }^{(65)}$, Sousa Santos nos invita a reflexionar sobre temas evidentes o inadvertidos, en todo caso cruciales para pensar este momento presente y futuros posibles a ser construidos. Nos pone a pensar: ies nuestro problema más crucial realmente la pandemia actual de COVID-19? ¿O ya estamos, hace algún tiempo, en una emergencia a escala planetaria que ahora visibiliza riesgos y potencializa peligros, siendo la pandemia solo una de estas amenazas? ¿Estamos pasando también en este momento por una crisis de pensamiento, esa matriz intelectual ilustrada, ahora incapaz de afrontar la sinrazón que rompe pactos políticos históricos? ¿Será que las crisis económicas y políticas derivadas del impacto de las estrategias de control pandémico tendrán algún horizonte de superación en este modo de producción, en este orden económico mundial y en esta coyuntura actual? ¿Estas crisis, y tantas otras, realmente aceleran la transformación de una forma de vida anticuada, preanunciando una transición de paradigma? ¿Cómo movilizar voluntades, generar energías, elaborar proyectos, desplegar acciones y organizar instituciones, a través de actos, declaraciones y compromisos articuladores de sujetos humanos y seres 
no humanos, con el objetivo de construir un mundo mejor, más justo, más solidario, más sustentable, más compartido, más vivo?

Para responder a tantas y tan relevantes preguntas, tomando la pandemia de COVID-19 como un evento crítico y un objeto complejo, quizás precisemos una "pandemiología".

Como hemos visto, pandemias como esta no se reducen a la aparición de un nuevo patógeno en el bioma terrestre, ni a los signos y síntomas inicialmente desconocidos de una nueva entidad mórbida, ni a curvas epidémicas e indicadores epidemiológicos, ni al proceso dinámico de diseminación y contagio, ni a la "infodemia" de fake-news, mitos y mentiras, ni al pánico que todo ello provoca, ni a las crisis económicas y políticas derivadas o asociadas a ella. Comprenden totalidades singulares que, al extremo, implican todos estos fenómenos y procesos, y mucho más, articulados a diversos elementos de comprensión y análisis, unificados por heurísticas integradoras que no se reducen a medidas, correlaciones, descripciones y narrativas. Esto abre la posibilidad de incorporar analíticamente las propiedades de subobjetos específicos y referentes (por ejemplo, a un tejido, un sistema inmunológico, una distribución poblacional, un programa de salud o un sistema de atención) para la comprensión sintética de un dispositivo heurístico total, mejor definido en términos de densidad, funcionalidad y diversidad. Para una comprensión útil de estas propiedades, debemos considerar la formación del fenómeno epidemiológico como un objeto complejo, mutante, sindémico, singular, embutido en una expansión abrupta a gran escala, es decir, pandémica.

Según la epistemología de la complejidad de Samaja ${ }^{(9,66)}$, tales objetos implican sistemas dinámicos que revelan propiedades de alta mutabilidad (alta tasa de variación según el contexto y nivel de ocurrencia) que, en muchos casos, resulta en plasticidad (capacidad de ajuste a condiciones o variaciones de contexto). Podemos decir que, para fenómenos epidemiológicos a escala global, como las pandemias en general, se trata de una plasticidad suprasistémica. En el caso de una pandemia como la del COVID-19, esta propiedad de plasticidad se lleva al extremo. Se trata de una mutabilidad sensible al contexto, por lo que podríamos hablar de la naturaleza sindémica y cambiante de la respuesta social que, en este caso, es eminentemente política.

Los objetos-modelo sobredeterminados, como una pandemia, pueden ser prototípicos para la deseada integración intertransdisciplinaria entre las ciencias biomoleculares (generadores de conocimiento desde la base físico-química-biológica), las ciencias clínicas (responsables del modelaje no numérico de los resultados de salud), las ciencias de la salud pública (productores de conocimiento demográfico o poblacional, típicamente en la forma de modelaje numérico de riesgos y factores), ciencias sociales (por ejemplo, con procesos macrosociales representados como composición de elementos en la base del modelo), lógica y semántica (para validar vínculos simbólicos entre patrones, vectores y determinantes expresados en submodelos y modelos sintéticos). Particularmente, con respecto a los procesos concretos de la realidad en salud, los esfuerzos creativos dirigidos a la producción de modelos sintéticos de este orden pueden ser relevantes para la construcción de objetos transdisciplinarios complejos.

En este contexto actual de intensa disputa retórica y feroz lucha teórica, esta pandemia representa sin duda una rica oportunidad para llevar a cabo de manera efectiva la construcción intertransdisciplinaria y transepistémica tan necesaria para la generación de soluciones integradoras, pertinentes y cuidadosas de los problemas complejos que surgen en los diferentes planos y dimensiones de esta grave crisis de salud. Espero que estas notas boaventuro-samajianas contribuyan de alguna manera para un mejor diálogo y articulación entre las diferentes matrices de pensamiento, diferentes disciplinas y diversos campos de conocimiento y prácticas en lo que puede ser una ganancia secundaria de esta grave crisis de salud, para el desarrollo de nuevas y prometedoras estrategias de investigación y acción sobre la pandemia de COVID-19 y otros eventos emergentes y contingentes, definidos por su singularidad y complejidad. 


\section{FINANCIAMIENTO}

Durante la escritura de este artículo, me fue otorgada la Beca de Productividad (Nivel I-A) del Conselho Nacional de Desenvolvimento Científico e Tecnológico de Brasil (CNPq Proc. 302.600/2008-6)

\section{AGRADECIMIENTOS}

Agradezco al Instituto de Estudos Avançados de la Universidade de São Paulo por haberme convocado en los últimos años como profesor visitante.

\section{CONFLICTO DE INTERESES}

El autor declara que no existen conflictos de interés.

\section{REFERENCIAS BIBLIOGRÁFICAS}

1. Agamben G, ŽiŽek Z, Nancy JL, Berardi F, López Petit S, Butler J, Badiou A, Harvey D, Han PC, Zibechi R, Galindo M, Gabriel M, Yañez González G, Manrique P, Preciado P. Sopa de Wuhan: Pensamiento contemporáneo en tiempos de pandemias. Buenos Aires: ASPO (Aislamiento Social Preventivo y Obligatorio), 2020.

2. Mignolo W. Epistemic disobedience and the decolonial option: A manifesto. Transmodernity. 2011;1(2):44-66.

3. Sousa Santos B. Introducción a las epistemologías del sur. En: Meneses MP, Bidaseca K, coords. Epistemologías del Sur. Buenos Aires: CLACSO, Coimbra; 2018. p. 25-64.

4. Arreaza ALV. Epidemiologia crítica: por uma práxis teórica do saber agir. Ciência \& Saúde Coletiva. 2012;17(4):1001-1013.

5. Breilh J. Epidemiología crítica: ciencia emancipadora e interculturalidad. Buenos Aires: Lugar Editorial; 2003.

6. Das V. Critical events: An anthropological perspective on contemporary India. New Delhi: Oxford University Press; 1996

7. Fecher B. Embracing complexity: Covid-19 is a case for academic collaboration and co-creation. Elephant in the Lab [Internet] 2020 [citado 10 mar 2021]. Disponible en: https://tinyurl.com/2xwr5me3.

8. Elliot N. Mediating nature. London: Routledge; 2006.

9. Samaja J. Epistemología de la Salud. Buenos Aires: Lugar Editorial; 2004.

10. Almeida-Filho N. Modelagem da pandemia Covid-19 como objeto complexo (notas samajianas). Estudos Avançados. 2020;34(99):97-117.

11. Horton R. Offline: COVID-19 is not a pandemic. The Lancet. 2020;396:874.

12. Singer M. A dose of drugs, a touch of violence, a case of AIDS: conceptualizing the SAVA syndemic. Free Inquiry in Creative Sociology. 1996;24(2):99-110.
13. Mendenhall E. Beyond comorbidity: a critical perspective of syndemic depression and diabetes in crosscultural contexts. Medical Anthropology Quarterly. 2015;30(4):462-478.

14. Kohrt BA, Carruth L. Syndemic effects in complex humanitarian emergencies: A framework for understanding political violence and improving multi-morbidity health outcomes. Social Science \& Medicine. 2020. doi: 10.1016/j.socscimed.2020.113378.

15. Singer $M$. Introduction to syndemics: A critical systems approach to public and community health. New York: Jossey-Bass; 2009.

16. Tsai AC, Venkataramani AS. Syndemics and health disparities: a methodological note. AIDS and Behavior. 2016;20(2):423-430.

17. Mendenhall E, Singer M. What constitutes a syndemic? Methods, contexts, and framing from 2019. Current Opinion in HIV and AIDS. 2020;15(4):213-217.

18. Valderas JM, Starfield B, Sibbald B, Salisbury C, Roland M. Defining comorbidity: implications for understanding health and health services. Annals of Family Medicine. 2009;7(4):357-363.

19. van den Akker M, Buntinx F, Knottnerus JA. Comorbidity or multimorbidity. The European Journal of General Practice. 1996;2(2):65-70.

20. Tsai AC. Syndemics: a theory in search of data or data in search of a theory? Social Science \& Medicine. 2018;206:117-122.

21. Tsai AC, Mendenhall E, Trostle JA, Kawachi I. Cooccurring epidemics, syndemics, and population health. The Lancet. 2017;389(10072):978-982.

22. Pranata R, Lim MA, Huang I, Raharjo SB, Lukito A. Hypertension is associated with increased mortality and severity of disease in COVID-19 pneumonia: A systematic review, meta-analysis and meta-regression. Journal of the Renin-Angiotensin-Aldosterone System. 2020;21(2):1470320320926899.

23. Rubino $F$, Amiel SA, Zimmet $P$, Alberti $G$, Bornstein S, Eckel RH, Renard E. (2020). New-onset diabetes in COVID-19. The New England Journal of Medicine. 2020;383:789-790.

24. Akoumianakis I, Filippatos T. The renin-angiotensinaldosterone system as a link between obesity and coronavirus disease 2019 severity. Obesity Reviews. 2020;21(9):e13077.

25. Gravlee CC. Systemic racism, chronic health inequities, and COVID-19: A syndemic in the making? American Journal of Human Biology. 2020;32(5):e23482.

26. Khazanchi R, Beiter ER, Gondi S, Beckman AL, Bilinski A, Ganguli I. County-level association of social vulnerability with COVID-19 cases and deaths in the USA. Journal of General Internal Medicine. 2020;35(9):27842787. 
27. Laster Pirtle WN. Racial capitalism: a fundamental cause of novel coronavirus (COVID-19) pandemic inequities in the United States. Health Education \& Behavior. 2020;47(4):504-508.

28. Singer M, Stopka T, Cara S, Springer K, George B, Kaveh K, Gorry de Puga A, Heimer R. The social geography of AIDS and hepatitis risk: qualitative approaches for assessing local differences in sterile syringe access among injection drug users. American Journal of Public Health. 2000;90(7):1049-1056.

29. Singer M. Pathogen-pathogen interaction: A syndemic model of complex biosocial processes in disease. Virulence. 2010;1(1):10-18.

30. Singer M, Bulled N, Ostrach B, Mendenhall E. Syndemics and the biosocial conception of health. The Lancet. 2017;389:941-950.

31. Almeida-Filho N. Towards a unified theory of healthdisease: II. Holopathogenesis. Revista de Saúde Pública. 2014;48(2):192-205.

32. Shrestha S, Bauer CXC, Hendricks B, Stopka TJ. Spatial epidemiology: An empirical framework for syndemics research. Social Science \& Medicine. 2020. doi: 10.1016/j.socscimed.2020.113352.

33. Fernández Iriarte $M$, Pompei J. No hay dos sin tres: Pandemia, infodemia y ahora también sindemia. Farmacia y Bioquímica en Foco [Internet]. 2021 [citado 13 ene 2021]. Disponible en: https://tinyurl.com/6zef2err.

34. Zarocostas J. How to fight an infodemic. The Lancet. 2020;395:676.

35. Patel MP, Kute VB, Agarwal SK, COVID-19 working group of Indian Society of Nephrology. "Infodemic" COVID 19: More pandemic than the Virus. Indian Journal of Nephrology. 2020;30(3):188-191.

36. Eysenbach G. Infodemiology: The epidemiology of (mis)information. American Journal of Medicine. 2002;113(9):763-765.

37. Eysenbach G. Infodemiology and infoveillance: framework for an emerging set of public health informatics methods to analyze search, communication and publication behavior on the Internet. Journal of Medical Internet Research. 2009;11(1):e11.

38. Porta $M$, ed. A Dictionary of Epidemiology. New York: Oxford University Press; 2014.

39. Rothkopf D. When the Buzz Bites Back. The Washington Post [Internet] 11 May 2003 [citado 10 ene 2021]. Disponible en: https://tinyurl.com/ywfumxz6.

40. Eysenbach G. How to fight an Infodemic: The four pillars of infodemic management. Journal of Medical Internet Research. 2020;22(6):e21820.

41. World Health Organization. Managing the COVID-19 infodemic: Promoting healthy behaviours and mitigating the harm from misinformation and disinformation [Internet]. 2020 [citado 10 ene 2021]. Disponible en: https://tinyurl.com/nsenunnr.
42. Organización Panamericana de la Salud, Revista Panamericana de Salud Pública. Número especial sobre infodemiología y manejo de la infodemia en la era de la interdependencia digital: convocatoria de artículos [Internet]. 2020 [citado 10 ene 2021]. Disponible en: https://tinyurl.com/u9bt4zes.

43. Omvärlden. "Vi står upp mot dem som försöker så splittring och förtvivlan" [Internet]. 2020 [citado 10 ene 2021]. Disponible en: https://tinyurl.com/d59rv8ck.

44. Garcia LP, Duarte E. Infodemia: excesso de quantidade em detrimento da qualidade das informações sobre a COVID-19. Epidemiologia e Serviços de Saúde. 2020;29(4):e2020186.

45. Darnton R. The true history of fake news. The New York Review [Internet]. 2017 [citado 10 ene 2021]. Disponible en: https://tinyurl.com/6bdrv58d.

46. Yap A, Snyder LG, Drye S. The information war in the digital society: A conceptual framework for a comprehensive solution to fake news. Academy of Social Science Journal. 2018;3(7):1214-1221.

47. Levinson P. Fake news in real context. New York: Connected Editions; 2016.

48. Lasco G. Medical populism and the COVID-19 pandemic. Global Public Health. 2020;15(10);1417-1429.

49. Alcantara J, Ferreira R. A infodemia da "gripezinha": uma análise sobre desinformação e coronavírus no Brasil. Chasqui: Revista Latinoamericana de Comunicación. 2020;(145):137-162.

50. Rocha C. O isolamento vertical defendido por Bolsonaro sob análise. Nexo [Internet]. 25 mar 2020 [citado 10 ene 2021]. Disponible en: https://tinyurl. com/36yz9bcf.

51. Hu B, Guo H, Zhou P, Shi ZL. Characteristics of SARS-CoV-2 and COVID-19. Nature Reviews Microbiology. 2021;19:141-154.

52. Friedman T. A plan to get America back to work. The New York Times [Internet]. 22 mar 2020 [citado 10 ene 2021]. Disponible en: https://tinyurl.com/kd4w6pn8.

53. Katz D. Is our fight against Coronavirus worse than the disease? The New York Times [Internet]. 20 mar 2020 [citado 10 ene 2021]. Disponible en: https:// tinyurl.com/88y3wyah.

54. Gabbatt A. Did a New York Times article inspire Trump's 'back to work' plan? The Guardian [Internet]. 27 mar 2020 [citado 10 ene 2021]. Disponible en: https:// tinyurl.com/49eu9yra.

55. Jones D, Helmreich S. A history of herd immunity. The Lancet. 2020;396:810-811.

56. Gallotti R, Valle F, Castaldo N, Sacco P, Domenico $M$. Assessing the risks of "infodemics" in response to COVID-19 epidemics. Nature Human Behaviour. 2020;4:1285-1293. 
57. Great Barrington Declaration. The Great Barrington Declaration [Internet]. 2020 [citado 10 ene 2021]. Disponible en: https://gbdeclaration.org.

58. Associação Brasileira de Saúde Coletiva. A farsa do manifesto Great Barrington [Internet]. 9 oct 2020 [citado 10 ene 2021]. Disponible en: https://tinyurl.com/ yx4mpfa5.

59. Associação Brasileira de Saúde Coletiva. Plano Nacional de Enfrentamento da Pandemia de Covid-19 [Internet]. Rio de Janeiro: Abrasco; 2020 [citado 10 ene 2021]. Disponible en: https://tinyurl.com/9mcfm $25 f$.

60. Pires LN. Carvalho L, Xavier LL. COVID-19 e desigualdade no Brasil. CEBES [Internet]. 6 abr 2020 [citado 10 ene 2021]. Disponible en: https://tinyurl.com/fmnd4s6s.

61. Almeida-Filho N. Desigualdades en salud: nuevas perspectivas teóricas. Salud Colectiva. 2020;16:e2751.

62. Falavigna M, Colpani V, Stein C, Azevedo L, Pontes C, Bagattini AM, Brito GV, et al. Diretrizes para o tra- tamento farmacológico da COVID-19: Consenso da Associação de Medicina Intensiva Brasileira, da Sociedade Brasileira de Infectologia e da Sociedade Brasileira de Pneumologia e Tisiologia. Revista Brasileira de Terapia Intensiva. 2020;32(2):166-196.

63. Agência Câmara de Notícias. Falta de remédios prejudica tratamento da Covid-19 nas UTIs, alertam médicos. Câmara dos Deputados [Internet]. 2020 [citado 10 ene 2021]. Disponible en: https://tinyurl.com/rb7n4k7u.

64. Shamasunder $\mathrm{S}$, Holmes $\mathrm{S}$, Goronga $\mathrm{T}$, Carrasco $\mathrm{H}$, Katz E, Frankfurter R, Keshavjee S. COVID-19 reveals weak health systems by design: Why we must re-make global health in this historic moment. Global Public Health. 2020;15(7):1083-1089.

65. Sousa Santos B. O futuro começa agora: da pandemia à utopia. São Paulo: Boitempo; 2021.

66. Samaja J. Desafios a la epidemiologia (pasos para una epidemiologia 'miltoniana'). Revista Brasileira de Epidemiologia. 2003;6(2):105-120.

\section{FORMA DE CITAR}

Almeida-Filho N. Sindemia, infodemia, pandemia de COVID-19: Hacia una pandemiología de enfermedades emergentes. Salud Colectiva. 2021;17:e3748 doi: 10.18294/sc.2021.3748.

Recibido: 8 ago 2021 | Aprobado: 5 oct 2021 | Publicado en línea: 4 nov 2021

Esta obra está bajo una licencia Creative Commons Atribución 4.0 Internacional (CC BY 4.0). Atribución - Se debe dar crédito de manera adecuada, brindar un enlace a la licencia, e indicar si se han realizado cambios. Puede hacerlo en cualquier forma razonable, pero no de forma tal que sugiera que usted o su uso tienen el apoyo de la licenciante. Sin restricciones adicionales - No se pueden aplicar términos legales ni medidas tecnológicas que restrinjan legalmente a otras personas a hacer cualquier uso permitido por la licencia. 